\title{
COSTA RICA (1800-1850): EL LEGADO COLONIAL Y LA GENESIS DEL CAPITALISMO
}

\section{Lowell Gudmundson}

En éste, el cuarto de dieciseis volúmenes de la serie patrocinada por el Centro de Investigaciones Históricas de la Universidad de Costa Rica, Molina intenta al menos resumir los resultados de una gran variedad de investigaciones históricas recientes. El autor se destaca tanto por una prosa atractiva, como por un enfoque que no se reduce al esquema "café-capitalismo-sociedad" característico de anteriores estudios suyos. Es más, si hay una sorpresa agradable en esta obra, está en el evidente interés y desarrollo de los estudios de "mentalité", siguiendo tanto a los modelos franco-ingleses como lo poco hecho en el ámbito local. Con una "historia social" así tan ampliamente definida mucho más queda por hacer que hubiese parecido el caso con una lectura de anteriores estudios suyos de tipo socioeconómico.

Conforme el título, la obra sugiere un continuo compromiso con la propuesta analítica de que el capital comercial rápidamente subordina a la producción campesina o

Iván Molina Jiménez, Colección Historia de Costa Rica, número 4, Editorial de la Universidad de Costa Rica. 
mercantil simple. De ahí, aún se nota lo que algunos podrían considerar un exagerado énfasis en los comerciantes, el comercio y el crédito, pero Molina es muy hábil en sugerir también lo complejo y contradictorio de los papeles y respuestas campesinos frente a tal situación. En efecto, muy poco hay de mecanicismo en la interpretación, aún cuando a veces el "capital comercial" adquiere un aspecto casi teleológico.

Lejos de ser un análisis de la sociedad sólo en términos económicos, este estudio ofrece una gran variedad de perspectivas cotidianas y descripciones sociales. La historia social así resumida va desde la distribución temática de libros circulantes entre la élite de la época, hasta las representaciones del "imaginario religioso", los patrones de la delincuencia, y las inmigraciones de comerciantes y profesionales y sus consecuencias. Y es precisamente en este campo de la historia social donde la indudable elegancia y estilo expresivos del autor rinden sus mayores frutos. Constituye hasta un modelo de redacción, capaz de contrarrestar la profunda renuencia del alumnado a leer tomos "tan aburridos" como los que, según ellos, escriben los historiadores.

Quizás el único aspecto desafortunado del texto radica en el uso excesivo de gráficos y tablas de material estadístico, el cual no soporta tal cuantificación, ya sea por el corto número de casos o la discontinuidad de la serie. Muchos de los 68 gráficos son muy útiles, pero el autor podría haber sido más discriminante en este aspecto de una obra, por lo demás muy pulida y profesional. Tanto en las ilustraciones como en el texto, la serie editorial mantiene los mismos niveles superiores de fabricaciones y materiales, así como el bajo costo, característicos de los primeros tres tomos de la serie. Como tal, representa la mejor introducción sintética existente a lo que se ha hecho en las últimas dos décadas en historia social para este período de historia costarricense. Quizás, de esta forma, las futuras generaciones de estudiantes universitarios lograrán acercarse un poco más a la historia social practicada por los investigadores, cuyos estudios monográficos raramente pasan de citas honoríficas o resúmenes en antologías hechas a la medida para Estudios Generales. De ser así, la colección "Historia de Costa Rica" habría logrado no sólo su acometido sino una virtual revolución pedagógica. 